\title{
Isolation and Amino Acid Sequences of Polypeptide Toxins in the Caribbean Sea Anemone Condylactis passiflora
}

\author{
Kazuo Shiomi, Xin-Yu Lin, Yuji Nagashima, \\ and Masami Ishida \\ Department of Food Science and Technology, Tokyo University of Fisheries, \\ Minato, Tokyo 108, Japan
}

(Received April 17, 1995)

\begin{abstract}
The aqueous extract of the Caribbean sea anemone Condylactis passiflora was potently lethal to crabs and weakly hemolytic to animal erythrocytes but had no toxicity in mice. Three polypeptide toxins (named $\mathrm{Cp} \mathrm{I}$, II, and III) with lethal activity against crabs were isolated by ion-exchange chromatography on DEAE- and CM-cellulose, gel filtration on Sephadex G-50, and reverse-phase HPLC on Nucleosil $300-7 \mathrm{C}_{18}$. The minimum lethal doses against crabs were estimated to be $7.3 \mu \mathrm{g} / \mathrm{kg}(\mathrm{Cp} \mathrm{I}), 7.9$ $\mu \mathrm{g} / \mathrm{kg}$ (Cp II), and $10 \mu \mathrm{g} / \mathrm{kg}$ (Cp III). The amino acid compositions of the three toxins are closely related to each other; they are all rich in Asx, Ser, Gly, and half-Cys and are devoid of Met. In addition, it is noticeable that $\mathrm{Cp}$ I and II contain an unusual amino acid, hydroxyproline. The complete amino acid sequences of $\mathrm{Cp}$ I and II were determined. Both toxins have 47 amino acid residues, among which as many as 43 residues including all 6 half-Cys residues are homologous. Comparison with the sequences of the known sea anemone toxins reveals that $\mathrm{Cp} \mathrm{I}$ and II are analogous to type 1 long neurotoxins but have some significant changes in their sequences.
\end{abstract}

Key words: sea anemone, Condylactis passiflora, polypeptide toxins, isolation, amino acid sequence

Sea anemones contain a variety of biologically active substances, typical of which are two classes of toxins, cytolysins and sodium channel binding neurotoxins. Anemone cytolysins are common basic proteins with molecular weights of $15000-21000 .{ }^{1)}$ They possess potent hemolytic activity that is inhibited by sphingomyelin. On the other hand, sodium channel binding neurotoxins that prolong and inhibit the inactivation process of sodium currents during depolarization are polypeptides with molecular weights of $3000-5000 .^{2)}$ They are further classified into three types, two (types 1 and 2) composed of long polypeptides containing 46-49 amino acid residues and one (type 3) of shorter polypeptides containing 27-31 residues. There is extensive sequence homology $(>60 \%)$ either within the type 1 toxins, isolated from the genera Anemonia ${ }^{3-5)}$ Anthopleura, ${ }^{6-8)}$ and Bunodosoma, ${ }^{9}$ or within the type 2 toxins, isolated from the genera Heteractis (formerly Radianthus) ${ }^{10-15)}$ and Stichodactyla (formerly Stoichactis). ${ }^{16)}$ Although a little sequence homology (about $30 \%$ ), such as the same locations of the 6 half-Cys residues, is seen between the type 1 and 2 toxins, both types of toxins are immunologically distinguished from each other. The type 3 neurotoxins, isolated from limited species of sea anemones, ${ }^{17-19)}$ have very little homology with the type 1 or 2 toxins.

Sea anemone toxins are relatively well characterized as described above. It is, however, possible that structually and/or functionally interesting toxins differing from usual cytolysins and neurotoxins will emerge in sea anemones, as in the cases of metridiolysin ${ }^{20)}$ from Metridium senile, a cholesterol-inhibitable cytolysin with a higher molecular weight, and calitoxin ${ }^{21)}$ from Calliactis parasitica, a poly- peptide neurotoxin with less structural relationship to the type 1-3 toxins. In view of this possibility, we recently screened for toxins in several species of sea anemones. As a result, polypeptide toxins containing an unusual amino acid, hydroxyproline, were newly found in the Caribbean sea anemone Condylactis passiflora. Furthermore, the $C$. passiflora toxins were analogous to type 1 long toxins but had a number of alterations in the amino acid residues conserved for the known type 1 toxins. The present paper deals with the isolation and amino acid sequences of $C$. passiflora toxins.

It should be pointed out that the sea anemone used in this study was very similar to Condylactis gigantea but could not be identified. Anemone specimens from the Caribbean Sea, which are similar or identical to C. gigantea, are often identified in hobby literature as $C$. passiflora. ${ }^{22)}$ For convenience, our sample is called $C$. passiflora throughout this paper, although the name of $C$. passiflora is not always recognized by taxonomists.

\section{Materials and Methods}

\section{Sea Anemone}

A live specimen (body weight about $60 \mathrm{~g}$ ) of $C$. passiflora, which had been captured in the Caribbean Sea and imported to Japan, was purchased from Hikaru Aquarium (Tokyo), in October 1994. It was transported alive in sea water to our laboratory and stored at $-20^{\circ} \mathrm{C}$ until use.

\section{Assay of Toxicity}

Specimens of the freshwater crab Potamon dehaani weighing about $5 \mathrm{~g}$ were purchased at the Tokyo Central 
wholesale Market. Various dilutions of a given sample were intrahaemocoelically injected into groups of two crabs at the junction between the body and the leg. The injection volume was fixed at $10 \mu \mathrm{l} / \mathrm{g}$. Toxicity was judged to be positive when both crabs of each group were killed within $\mathbf{2} \mathbf{h}$ after injection, and was expressed in terms of crab unit (CU), where $1 \mathrm{CU}$ was defined as the minimum amount of toxin to kill a $5 \mathrm{~g}$ crab, or in terms of minimum lethal dose $(\mu \mathrm{g} / \mathrm{kg})$.

Toxicity was also assayed using male mice (ddY strain) weighing about $20 \mathrm{~g}$ purchased from Sankyo Labo Service (Tokyo). Sample solutions were intravenously injected into mice at $10 \mu \mathrm{l} / \mathrm{g}$ and the mice observed for 1 day.

\section{Assay of Hemolytic Activity}

Hemolytic activity against animal (cow, horse, sheep, and rabbit) erythrocytes was measured by the method of Shiomi et al. $^{23)}$ and expressed in hemolytic unit (HU), where $1 \mathrm{HU}$ was defined as the amount of toxin causing $50 \%$ hemolysis.

\section{Isolation Method}

In each column chromatography described below, proteins were followed by absorbance at $280 \mathrm{~nm}$ and toxins by lethal activity to crabs.

The frozen sample of $C$. passiflora was thawed and macerated in a motor. Thirty grams of the macerated sample were extracted twice with 2 volumes of distilled water and the extract was dialyzed using a Spectra/Por 6 membrane (molecular weight cut off 1000; Spectrum Medical Industries, TX, USA) against $10 \mathrm{mM}$ phosphate buffer $(\mathrm{pH}$ 7.0). The inner solution was applied to a DEAE-cellulose column $(1.5 \times 22 \mathrm{~cm})$, which was eluted with $10 \mathrm{mM}$ phosphate buffer ( $\mathrm{pH} 7.0$ ), followed by $1 \mathrm{M} \mathrm{NaCl}$ in the same buffer. Toxic fractions were combined and put onto a CMcellulose column $(1.5 \times 22 \mathrm{~cm})$, which was successively eluted with $10 \mathrm{~mm}$ phosphate buffer $(\mathrm{pH} 7.0)$ and $1 \mathrm{M} \mathrm{NaCl}$ in the buffer. Toxin-containing fractions were pooled and lyophilized. The dried material was dissolved in $5 \mathrm{ml}$ of 10 mu phosphate buffer ( $\mathrm{pH} 7.0$ ) containing $0.15 \mathrm{M} \mathrm{NaCl}$ and chromatographed on a Sephadex G-50 column $(2.2 \times 46$ $\mathrm{cm})$. Active fractions were combined and subjected to reverse-phase high performance liquid chromatography (HPLC) on a Nucleosil $300-7 \mathrm{C}_{18}$ column $(0.46 \times 25 \mathrm{~cm}$; Macherey-Nagel, Germany). Elution was achieved at a constant flow rate of $1 \mathrm{ml} / \mathrm{min}$ by a gradient (see Fig. 2 for detail) of acetonitrile in $0.1 \%$ trifluoroacetic acid (TFA). Thus, three toxins, named $\mathrm{Cp} \mathrm{I,} \mathrm{II,} \mathrm{and} \mathrm{III,} \mathrm{were} \mathrm{isolated.}$

\section{Protein Determination}

Protein was determined by the method of Lowry et $a l .,{ }^{24)}$ using bovine serum albumin as a standard.

\section{Amino Acid Analysis}

Each isolated toxin (about $200 \mu \mathrm{g}$ ) was hydrolyzed with $0.3 \mathrm{~m} /$ of $4 \mathrm{~N}$ methanesulfonic acid containing $0.2 \% 3-(2-$ aminoethyl) indole in an evacuated tube at $115^{\circ} \mathrm{C}$ for $24 \mathrm{~h}$. After hydrolysis, the solution was neutralized with an equal volume of $3.5 \mathrm{M} \mathrm{NaOH}$ and diluted with $1 \mathrm{~m} l$ of 0.2 M citrate buffer ( $\mathrm{pH} 2.2$ ). A $0.2 \mathrm{~m} /$ portion of the dilution was applied to an Atto MLC-703 amino acid analyzer.

\section{$S$-Carboxamidomethylation of $\mathrm{Cp} I I$}

Cp II $(350 \mu \mathrm{g})$ was dissolved in $1 \mathrm{ml}$ of $0.5 \mathrm{M}$ Tris- $\mathrm{HCl}$ buffer ( $\mathrm{pH} 8.5$ ) containing $6 \mathrm{M}$ guanidine- $\mathrm{HCl}$ and $2.5 \mathrm{~mm}$ EDTA and reduced with $2 \mathrm{mg}$ of dithiothreitol for $1 \mathrm{~h}$ at room temperature. Then, $20 \mathrm{mg}$ of iodoacetamide was added and the reaction mixture was kept at room temperature for $1 \mathrm{~h}$. The $S$-carboxamidomethylated (CAM) derivative produced was isolated by reverse-phase HPLC on a TSK ODS-80Ts column $(0.46 \times 15 \mathrm{~cm}$; Tosoh, Tokyo), using a linear gradient of acetonitrile $(0-70 \%$ in $60 \mathrm{~min})$ in $0.1 \%$ TFA.

\section{Enzymatic Degradation}

$\mathrm{Cp} \mathrm{I}$ and II (50 $\mu \mathrm{g}$ each) were individually digested with $0.1 \mathrm{mU}$ of asparaginylendopeptidase (EC 3.4.22.34; Takara Shuzo, Otsu) in $0.2 \mathrm{ml}$ of $50 \mathrm{~mm}$ sodium acetate buffer ( $\mathrm{pH} \mathrm{5.0)}$, containing $10 \mathrm{~mm}$ dithiothreitol and $1 \mathrm{~mm}$ EDTA, at $37^{\circ} \mathrm{C}$ for $24 \mathrm{~h}$. CAM-Cp II $(70 \mu \mathrm{g})$ was digested with $2 \mu \mathrm{g}$ of trypsin treated with L-(tosylamido-2-phenyl) ethyl chloromethyl ketone (EC 3.4.21.4; Worthington Biochemical, NJ, USA) in $0.3 \mathrm{ml}$ of $50 \mathrm{~mm}$ ammonium bicarbonate at $37^{\circ} \mathrm{C}$ for $22 \mathrm{~h}$. The peptide fragments generated by each enzymatic digestion were separated by reverse-phase HPLC on the above TSK ODS-80Ts column using a gradient (see Figs. 3-5 for detail) of acetonitrile in $0.1 \%$ TFA.

\section{Sequence Analysis}

Sequence analysis was performed on an automatic gasphase protein sequencer (LF-3400D TriCart with high sensitivity chemistry; Beckman, CA, USA). Cysteine was detected as PTH-dehydroalanine-dithiothreitol in the samples without $S$-carboxamidomethylation. Prior to analysis, the native sample ( $2 \mathrm{nmol})$ of $\mathrm{Cp}$ I or II was reduced in $10 \% 2$-mercaptoethanol at $70^{\circ} \mathrm{C}$ for $60 \mathrm{~min}$. Peptide samples $(0.3-1 \mathrm{nmol})$ isolated from each enzymatic digest were directly applied to the sequencer.

\section{Results}

\section{Toxicity}

The crude extract of $C$. passiflora was potently lethal to crabs $(3840 \mathrm{CU} / \mathrm{m} l)$ but its intravenous injection into mice caused neither signs of illness nor death. The crabs challenged with lethal doses exhibited tonic paralysis in legs, followed by occasional convulsion, and died within 2 h. Due to tonic paralysis in legs, the crabs that were placed on their back became unable to return to their normal position at least within $30 \mathrm{~min}$. In order to save time, therefore, toxicity was often checked by observing the crabs that were placed on their back $30 \mathrm{~min}$ after injection. In addition to the lethality to crabs, hemolytic activity was also displayed by the crude extract. However, since the estimated hemolytic activity ranging from $64 \mathrm{HU} / \mathrm{m} l$ (against rabbit erythrocytes) to $370 \mathrm{HU} / \mathrm{ml}$ (against cow erythrocytes) was rather weak probably due to a small amount of cytolysins, isolation was directed only to the toxins having lethal activity against crabs.

\section{Isolation of Toxins}

The $C$. passiflora toxins were retained neither by DEAEcellulose nor by CM-cellulose (data not shown). By pass- 
ing through both DEAE- and CM-cellulose columns, about $80 \%$ of proteins contained in the crude extract were removed. When the active fractions obtained by ion-exchange chromatography were subjected to gel filtration on Sephadex G-50, three peaks with absorbance at $280 \mathrm{~nm}$ appeared; crab toxicity was detected only in the second peak (Fig. 1). Isolation of three toxins (Cp I, II, and III) was finally achieved by reverse-phase HPLC (Fig. 2). As summarized in Table $1,30 \mathrm{~g}$ of the starting material afforded

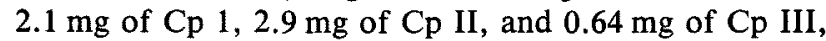
with a total recovery in toxicity of $25 \%$. The minimum lethal doses against crabs were estimated to be $7.3 \mu \mathrm{g} / \mathrm{kg}$ for $\mathrm{Cp} \mathrm{I,} 7.9 \mu \mathrm{g} / \mathrm{kg}$ for Cp II, and $10 \mu \mathrm{g} / \mathrm{kg}$ for Cp III.

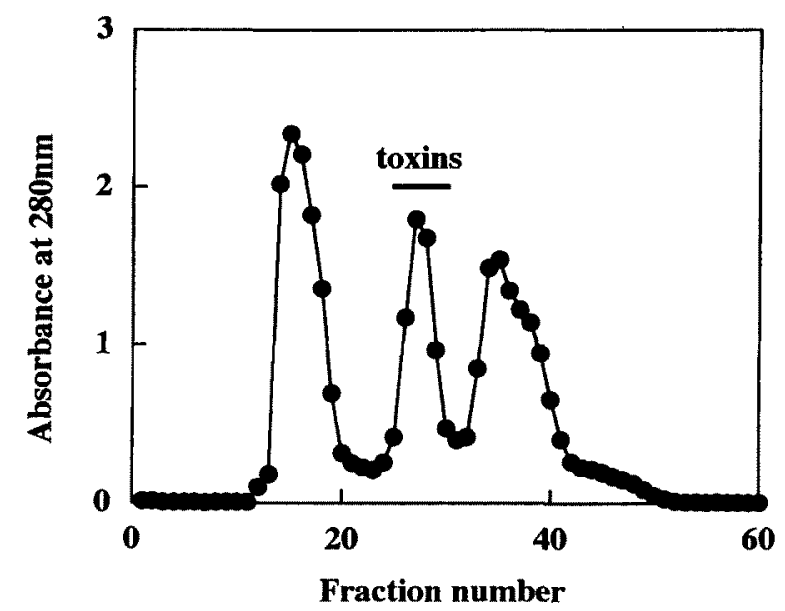

Fig. 1. Gel filtration of toxins.

Toxic fractions obtained by ion-exchange chromatography of the crude extract were applied to a Sephadex G-50 column $(2.2 \times 46 \mathrm{~cm})$, which was eluted with $0.15 \mathrm{M} \mathrm{NaCl}$ in $10 \mathrm{~mm}$ phosphate buffer (pH 7.0). Fractions of $4 \mathrm{~m} /$ were collected.

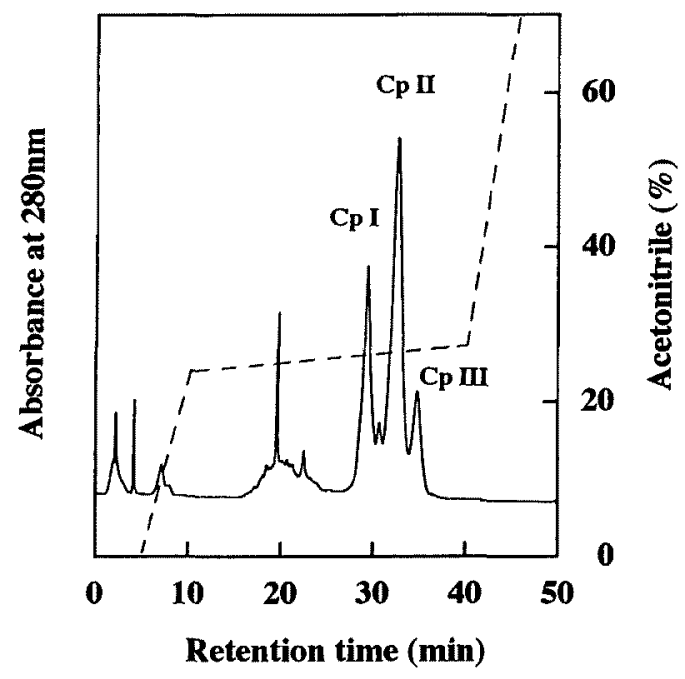

Fig. 2. Separation of toxins by reverse-phase HPLC.

Toxic fractions obtained by gel filtration (see Fig. 1) were subjected to a Nucleosil $300-7 \mathrm{C}_{18}$ column $(0.46 \times 25 \mathrm{~cm})$. After washing with $0.1 \%$ TFA, the column was eluted with a gradient (represented by the dotted line) of acetonitrile in $0.1 \%$ TFA. The flow rate was maintained at $1 \mathrm{ml} / \mathrm{min}$.
As shown in Table 2, the amino acid compositions of Cp I, II, and III were closely similar to one another. All toxins were rich in Asx, Ser, Gly, and half-Cys and lacked Met. However, there were some obvious differences among the three toxins. $\mathrm{Cp}$ I did not contain Tyr, while the other two toxins were devoid of Phe, instead of Tyr. Moreover, both $\mathrm{Cp}$ I and II contained an unusual amino acid, hydroxyproline, which was distinguishable from $\mathrm{Cp}$ III.

\section{Amino Acid Sequences of $\mathrm{Cp} I$ and II}

When the reduced sample of $\mathrm{Cp}$ I was analyzed by a sequencer, 37 amino acid residues from the $\mathrm{N}$-terminus were identified. In order to determine the rest of the sequence, Cp I was digested with asparaginylendopeptidase. Two peptide fragments (I-N1 and I-N2) were isolated from the digest by reverse-phase HPLC (Fig. 3) and sequenced. In the case of Cp II, $28 \mathrm{~N}$-terminal amino acid residues were identified by sequence analysis of the reduced sample. After digestion of the toxin with asparaginylendopeptidase, 2 peptides (II-N1 and II-N2) were isolated by reverse-phase

Table 1. Summary of toxin isolation

\begin{tabular}{lcccc}
\hline Isolation step & $\begin{array}{c}\text { Protein } \\
(\mathrm{mg})\end{array}$ & $\begin{array}{c}\text { Total } \\
\text { toxicity } \\
(\mathrm{CU})\end{array}$ & $\begin{array}{c}\text { Recovery } \\
\text { in toxicity } \\
(\%)\end{array}$ & $\begin{array}{c}\text { Minimum } \\
\text { lethal dose } \\
(\mu \mathrm{g} / \mathrm{kg})\end{array}$ \\
\hline Crude extract & 387 & $5760 \times 10^{2}$ & 100 & 134 \\
DEAE-cellulose & 106 & 4860 & 84 & 44 \\
CM-cellulose & 73 & 4220 & 73 & 35 \\
Sephadex G-50 & 21 & 3080 & 53 & 14 \\
Nucleosil 300-7C & & & & \\
Cp I & 2.1 & 572 & 10 & 7.3 \\
Cp II & 2.9 & 730 & 13 & 7.9 \\
Cp III & 0.64 & 128 & 2 & 10 \\
\hline
\end{tabular}

Isolation of toxins was performed using $30 \mathrm{~g}$ of sample.

Table 2. Amino acid compositions of $\mathrm{Cp}$ I, II, and III

\begin{tabular}{llll}
\hline & \multicolumn{3}{c}{ No. of residue ${ }^{* 1}$} \\
\cline { 2 - 4 } Amino acid & Cp I & Cp II & Cp III \\
\cline { 2 - 4 } Asx & $4.9(5)$ & $6.2(6)$ & 6.0 \\
Hyp ${ }^{* 2}$ & $1.0(1)$ & $0.9(1)$ & 0.0 \\
Thr & $3.0(3)$ & $2.1(2)$ & 2.0 \\
Ser & $4.7(5)$ & $4.8(5)$ & 4.8 \\
Glx & $3.3(3)$ & $3.5(3)$ & 3.4 \\
Pro & $1.1(1)$ & $1.0(1)$ & 2.3 \\
Gly & $6.6(6)$ & $6.9(6)$ & 6.9 \\
Ala & $1.1(1)$ & $2.1(2)$ & 2.1 \\
Val & $4.4(4)$ & $3.8(4)$ & 3.9 \\
Cys (half) & $5.0(6)$ & $4.9(6)$ & 4.3 \\
Met & $0.0(0)$ & $0.0(0)$ & 0.0 \\
Ile & $1.0(1)$ & $1.0(1)$ & 1.1 \\
Leu & $1.2(1)$ & $1.1(1)$ & 1.2 \\
Tyr & $0.1(0)$ & $1.9(2)$ & 2.1 \\
Phe & $1.0(1)$ & $0.0(0)$ & 0.0 \\
His & $3.5(4)$ & $1.7(2)$ & 1.7 \\
Trp & $2.2(2)$ & $2.1(2)$ & 1.9 \\
Lys & $1.9(2)$ & $2.0(2)$ & 2.0 \\
Arg & $1.0(1)$ & $0.9(1)$ & 1.1 \\
\hline
\end{tabular}

*1 Calculated on the basis that total residues are 47 for all toxins. The numbers in parentheses for $\mathrm{Cp}$ I and II are from the sequence analysis.

*2 Hyp represents hydroxyproline. 


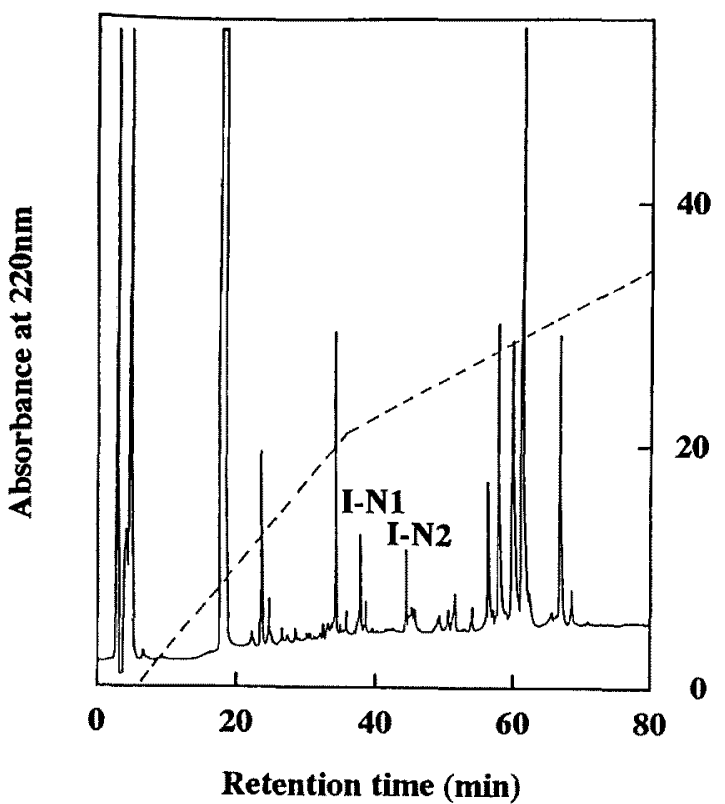

Fig. 3. Reverse-phase HPLC of the peptides produced by digestion of $\mathrm{Cp}$ I with asparaginylendopeptidase.

Column, TSK ODS-80Ts $(0.46 \times 15 \mathrm{~cm})$; elution, gradient (represented by dotted line) of acetonitrile in $0.1 \%$ TFA; flow rate, $1 \mathrm{~m} / / \mathrm{min}$; detection, absorbance at $220 \mathrm{~nm}$.

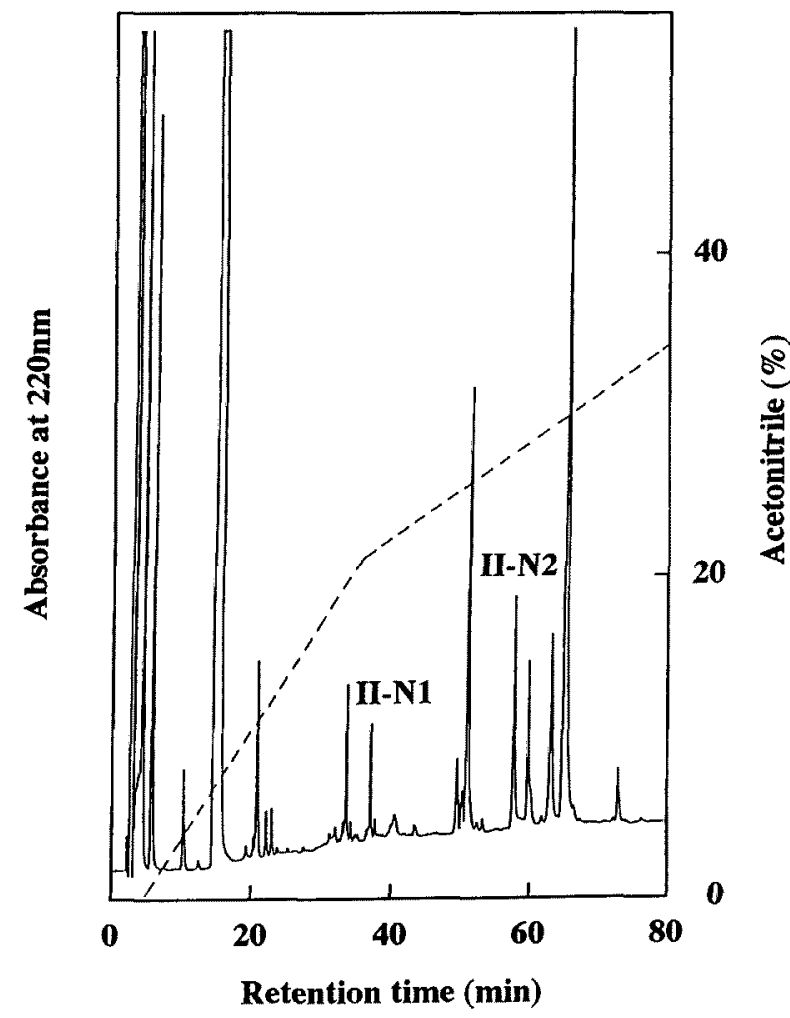

Fig. 4. Reverse-phase HPLC of the peptides produced by digestion of Cp II with asparaginylendopeptidase. HPLC conditions as in Fig. 3.

HPLC (Fig. 4) and subjected to sequencing. Furthermore, 1 peptide fragment (II-T1) was isolated from the tryptic

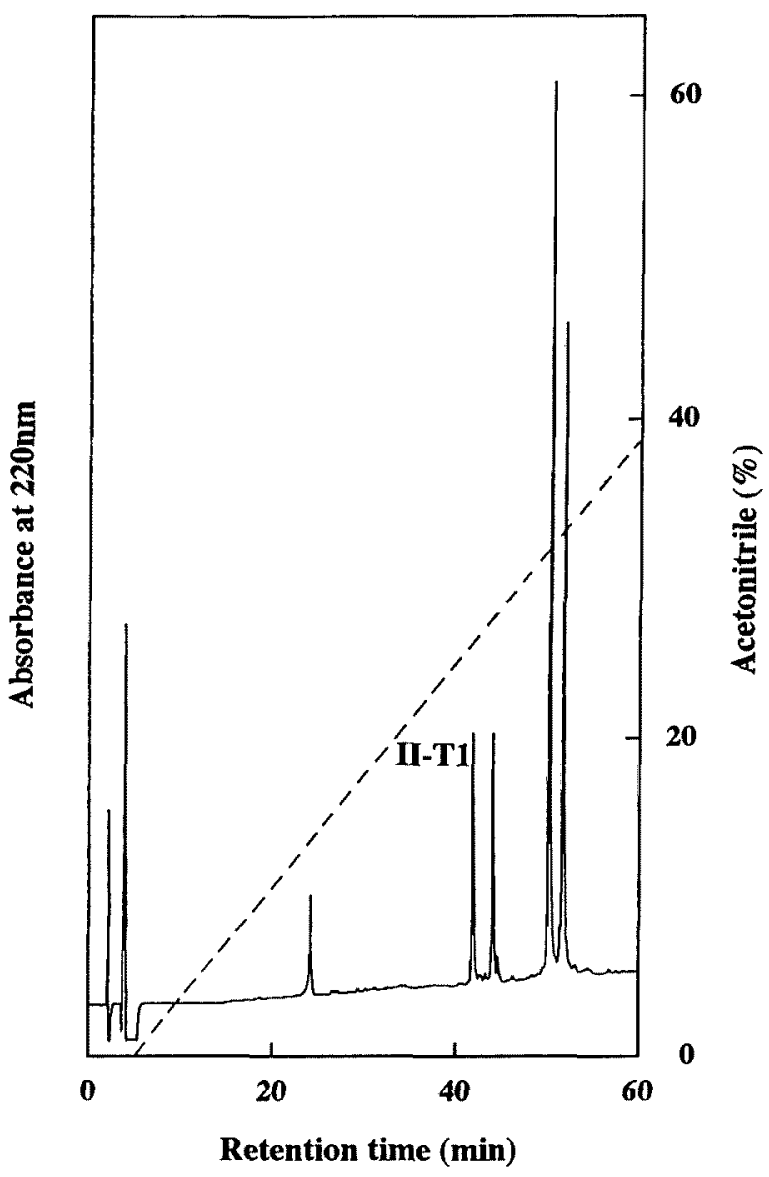

Fig. 5. Reverse-phase HPLC of the peptides produced by digestion of Cp II with trypsin.

HPLC conditions as in Fig. 3.

digest of CAM-Cp II by reverse-phase HPLC (Fig. 5) and also sequenced. Figure 6 shows the complete amino acid sequences of $\mathrm{Cp}$ I and II, together with the sequence data obtained for the native toxins and the enzymatic fragments. There was extensive high sequence homology $(91 \%)$ between the two toxins, both of which were composed of 47 amino acid residues including 6 half-Cys residues. Both toxins had identical 35 amino acid residues from the $\mathrm{N}$-terminus and identical locations of the 6 half-Cys residues, with only four changes at positions 36 (Thr/Asp), 38 (His/Tyr), 41 (Phe/Ala), and 42 (His/Tyr). In this study, the locations of the 3 disulfide bonds were not examined.

\section{Discussion}

The sea anemone C. passiflora was newly found to contain polypeptide toxins, together with a small amount of cytolysins. Three toxins were effectively isolated by a combination of ion-exchange chromatography, gel filtration, and reverse-phase HPLC. Although another minor toxin was suggested to exist by the elution profile in reversephase HPLC in which a small peak was observed between $\mathrm{Cp}$ I and II (Fig. 2), its purification was not carried out in this study. The toxins were all assumed to be very stable during the isolation procedure. Thus, the estimated mini- 


$1 \quad 10 \quad 20 \quad 30 \quad 40$

CPI GVHYCRCDSDGPSVHGNTLSGTVWVGSCASGWHKCNTEHNIFHECCKE

Native

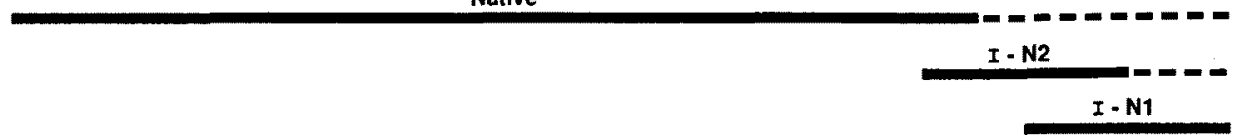
10
20
30

1

CPII GVHYPCRDSDGPSVHGNTLSGTVWVGSCASGWHKCNDEYN IAYECCKE

Native

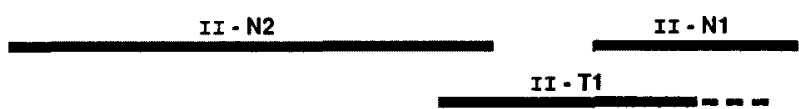

Fig. 6. Amino acid sequences of $\mathrm{Cp} \mathrm{I}$ and II.

The sequences of the N-terminal portion (native), asparaginylendopeptidase peptides (I-N1, I-N2, II-N1, and II-N2) and tryptic peptide (II-T1) were determined. Broken lines indicate the portions not analyzed. Hyp at position 3 in both toxins represents hydroxyproline.

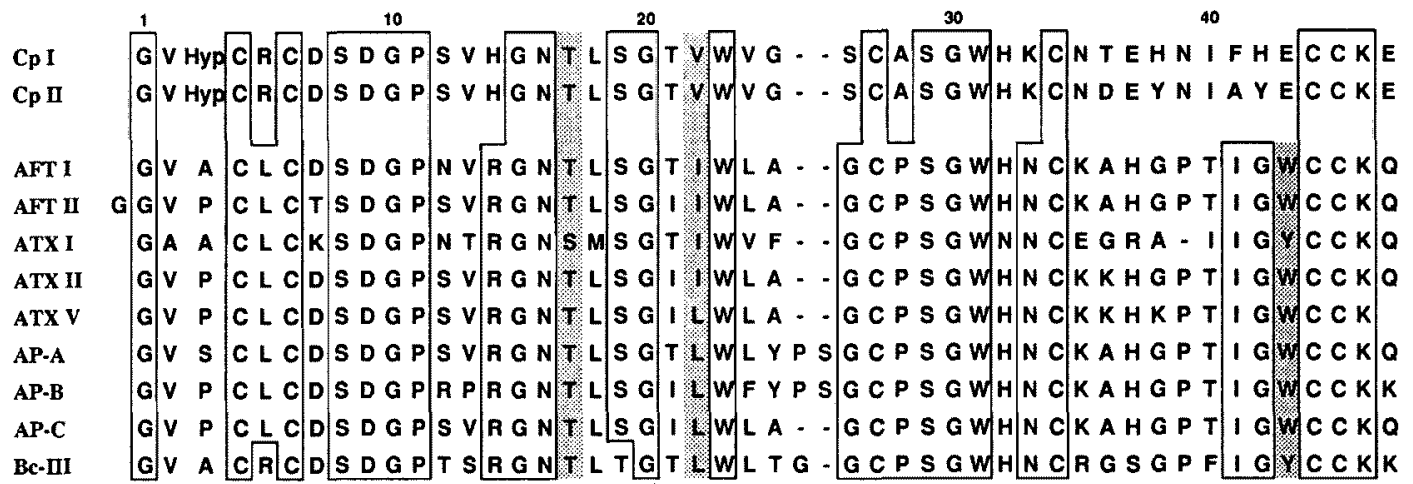

Fig. 7. Amino acid sequences of type 1 long toxins from sea anemones.

The upper two lines show the sequences of toxins ( $\mathrm{Cp}$ I and $\mathrm{Cp}$ II) from Condylactis passiffora under study. Hyp at position 3 in both toxins represents hydroxyproline. Other sequence data of toxins were modified from Norton ${ }^{2)}$ and Malpezzi.9) The residues which are boxed and those which are shaded were previously reported to be identical and conservatively substituted, respectively, by Norton. ${ }^{2)}$ AFT I and AFT II are obtained from Anthopleura fuscoviridis; ATX I, ATX II, and ATX V from Anemonia sulcata; AP-A and AP-B from Anthopleura xanthogrammica; AP-C from Anthopleura elegantissima; Bc III from Bunodosoma caissarum.

mum lethal doses against crabs of the isolated toxins (7.3$10 \mu \mathrm{g} / \mathrm{kg}$ ) are comparable to the values reported for other sea anemone neurotoxins. ${ }^{2)}$ In contrast, the toxins are much less toxic or substantially non-toxic to mice, since intravenous injection of the crude extract exhibits no toxicity in mice. This high crustacean but low mammalian toxicity has also been recognized for some sea anemone neurotoxins such as ATX I of Anemonia sulcata and Sh I of Stichodactyla helianthus. $\left.{ }^{2}\right)$

The amino acid compositions of $C$. passiflora toxins are similar to those of the four toxins isolated from another Condylactis species ( $C$. aurantiaca). ${ }^{25)}$ However, our toxins are devoid of Met as in the case of almost all neurotoxins from sea anemones, while those of $C$. aurantiaca are not. With respect to the amino acid composition of $C$. passiflora toxins, it is especially worth mentioning that $\mathrm{Cp} \mathrm{I}$ and II contain an unusual amino acid, hydroxyproline. Although this amino acid is abundant in collagens and also is known to be a constituent of conotoxins, ${ }^{26)}$ polypeptide neurotoxins isolated from the cone shell Conus geographus, it is not contained in the sea anemone polypeptide toxins known to date. In this connection, it is in- teresting to note that our preliminary experiments also suggest the occurrence of hydroxyproline in a polypeptide toxin from another sea anemone Heteractis (Radianthus) crispus (unpublished data). Hydroxyproline may be more widely distributed in sea anemone toxins than expected.

Our determinations of the amino acid sequences for $\mathrm{Cp}$ I and II are reliable, even without confirmation of the Cterminal sequence by any specific method such as the carboxypeptidase method. It is obvious that the number of each amino acid obtained from sequence analysis agrees well with that estimated from amino acid analysis, only with a slight difference for Gly and half-Cys in both toxins (Table 2). Furthermore, the I-N1 and II-N1 fragments produced by treatment with asparaginylendopeptidase, having Glu as the C-terminal residue, are easily assignable to be the C-terminal peptides of $\mathrm{Cp} \mathrm{I}$ and II, respectively, since the enzyme specifically cleaves the peptide bond at the carboxyl site of Asn. In the case of Cp I, the I-N2 fragment accounts for the gap between the sequence of 37 residues from the $\mathrm{N}$-terminus and that of $\mathrm{I}-\mathrm{N} 1$ (C-terminal peptide), although it is produced as a result of incomplete digestion, that is, the peptide bond between Asn-39 and 
Ile- 40 is not cleaved. On the other hand, in the case of $\mathrm{Cp}$ Il, the two enzymatic fragments, II-N2 and II-TI, apparently make amends for the portion (between Ser-29 and Asn-39) which has remained unknown after analyses of the native sample and the fragment II-N1.

It is obvious that the $C$. passiflora toxins have high sequence homology with the type 1 long toxins isolated from other species of sea anemones. For comparison, together with the sequences of $\mathrm{Cp} \mathrm{I}$ and II, those of the following type 1 toxins determined to date are shown in Fig. 7: AFT $\mathrm{I}^{6}$ and AFT $\mathrm{II}^{6)}$ isolated from Anthopleura fuscoviridis,

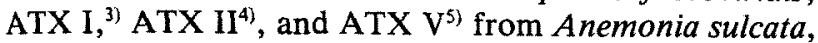
AP-A ${ }^{7}$ and $\mathrm{AP}-\mathrm{B}^{8)}$ from Anthopleura xanthogrammica, $\mathrm{AP}-\mathrm{C}^{2)}$ from Anthopleura elegantissima and $\mathrm{Bc} \mathrm{III')} \mathrm{from}$ Bunodosoma caissarum. Since the locations of the 6 halfCys residues are invariable in all toxins, it is relevant to consider that the 3 disulfide bonds involved in both $\mathrm{Cp} I$ and II are conservatively located between Cys-4 and -44 , Cys-6 and -34 , and Cys-27 and -45 , as reported for AFT I and $\mathrm{II}^{()}$and ATX I. ${ }^{3)}$ Previously, Norton ${ }^{2)}$ compared 8 kinds of type 1 toxins (AFT I, AFT II, ATX I, ATX II, ATX V, AP-A, AP-B, and AP-C) as to their amino acid sequences and pointed out that 27 amino acid residues are homologous and 3 residues are conservatively substituted throughout all toxins. For Bc III, only two alternations are found in the homologous amino acid residues, Leu- 5 being replaced by Arg and Ser-19 by Thr. On the other hand, both $\mathrm{Cp}$ I and II have a number of changes in either homologous or conservatively substituted amino acid residues, viz. Leu-5 to Arg, Arg-14 to His, Gly-26 to Ser, Pro-28 to Ala, Asn-33 to Lys, Ile-41 to Phe (Cp I) or Ala (Cp II), Gly-42 to His (Cp I) or Tyr (Cp II), and Trp/Tyr43 to Glu. Thus, the homology of Cp I or II with other type 1 toxins is rather low (47-60\%), compared to the statement of Norton ${ }^{2)}$ that there is more than $60 \%$ homology within type 1 toxins. Of the observed changes, the replacement of Arg-14, the only residue being clearly functional, by $\mathrm{His}$ is of particular importance.

In conclusion, the $C$. passiflora toxins are structurally unique compared with the known type 1 neurotoxins; they contain an unusual amino acid, hydroxyproline, and have many changes, including the significant replacement of Arg-14 by His, in their sequences. Though not confirmed, it is very likely that the $C$. passiflora toxins act essentially in the same manner as the known type 1 toxins. Valuable information concerning the structure-function relationship of type 1 toxins will be provided by future study with the C. passiflora toxins.

Acknowledgments The authors thank Dr. A. Shinagawa, Gakushuin Women's College, for measuring the amino acid compositions and $\mathrm{Mr}$. W.-H. Qian in our department for his technical assistance.

\section{References}

1) W. R. Kem: Sea anemone toxins: structure and action, in "The Biology of Nematocystes" (ed. by D. A. Hessinger and H. M. Lenhoff), Academic Press, New York, 1988, pp. 375-405.

2) R. S. Norton: Structure and structure-function relationships of sea anemone proteins that interact with the sodium channel. Toxicon, 29, 1051-1084 (1991).

3) G. Wunderer and M. Eulitz: Amino acid sequence of toxin I from Anemonia sulcata. Eur. J. Biochem., 89, 11-17 (1978).

4) G. Wunderer, H. Fritz, E. Wachter, and W. Machleidt: Amino acid sequence of a coelenterate toxin: toxin II from Anemonia sulcata. Eur. J. Biochem., 68, 193-198 (1976).

5) J. J. Scheffler, A. Tsugita, G. Linden, H. Schweitz, and M. Lazdunski: The amino acid sequence of toxin V from Anemonia sulcata. Biochim. Biophys, Res. Commun., 107, 272-278 (1982).

6) S. Sunahara, K. Muramoto, K. Tenma, and H. Kamiya: Amino acid sequence of two sea anemone toxins from Anthopleura fuscoviridis. Toxicon, 25, 211-219 (1987).

7) M. Tanaka, M. Haniu, K. T. Yasunobu, and T. R. Norton: Amino acid sequence of the Anthopleura xanthogrammica heart stimulant anthopleurin-A. Biochemistry, 16, 204-208 (1977).

8) N. S. Reimer, C. L. Yasunobu, K. T. Yasunobu, and T. R. Norton: Amino acid sequence of the Anthopleura xanthogrammica heart stimulant, anthopleurin-B. J. Biol. Chem., 260, 8690-8693 (1985).

9) E. L. A. Malpezzi, J. C. De Freitas, K. Muramoto, and H. Kamiya: Characterization of peptides in sea anemone venom collected by a novel procedure. Toxicon, 31, 853-864 (1993).

10) T. A. Zykova and E. P. Kozlovskaya: Amino acid sequence of neurotoxin I from the sea anemone Radianthus macrodactylus. Bioorg. Khim., 15, 1301-1306 (1989).

11) T. A. Zykova, E. P. Kozlovskaya, and G. B. Elyakov: Amino acid sequence of neurotoxin II from the sea anemone Radianthus macrodactylus. Bioorg. Khim., 14, 878-882 (1988).

12) T. A. Zykova, L. M. Vinokurov, E. P. Kozlovskaya, and G. B. Elyakov: Amino acid sequence of neurotoxin III from the sea anemone Radianthus macrodactylus. Bioorg. Khim., 11, 302-310 (1985).

13) T. A. Zykova, E. P. Kozlovskaya, and G. B. Elyakov: Amino acid sequence of neurotoxins IV and $\mathrm{V}$ from the sea anemone Radianthus macrodactylus. Bioorg. Khim., 14, 1489-1494 (1988).

14) D. E. Wemmer, N. V. Kumar, R. M. Metrione, M. Lazdunski, G. Drobny, and N. R. Kallenbach: NMR analysis and sequence of toxin II from the sea anemone Radianthus paumotensis. Biochemistry, 25, 6842-6849 (1986).

15) R. M. Metrione, H. Schweitz, and K. A. Walsh: The amino acid sequence of toxin Rp III from the sea anemone Radianthus paumotensis. FEBS Lett., 218, 59-62 (1987).

16) W. R. Kem, B. Parten, M. W. Pennington, D. A. Price, and B. M. Dunn: Isolation, characterization and amino acid sequence of a polypeptide neurotoxin occurring in the sea anemone Stichodactyla helianthus. Biochemistry, 28, 3483-3489 (1989).

17) L. Beress, G. Wunderer, and E. Wachter: Amino acid sequence of toxin III from Anemonia sulcata. Hoppe-Seyler's Z. Physiol. Chem., 358, 985-988 (1977).

18) G. Martinez, C. Kopeyan, H. Schweitz, and M. Lazdunski: Toxin III from Anemonia sulcata: primary structure. FEBS Lett, 84, 247-252 (1977).

19) S. Nishida, S. Fujita, A. Warashina, M. Satake, and N. Tamiya: Amino acid sequence of a sea anemone toxin from Parasicyonis actinostoloides. Eur. J. Biochem., 150, 171-173 (1985).

20) A. W. Bernheimer and L. S. Avigad: A cholesterol-inhibitable protein from the sea anemone Metridium senile. Biochim. Biophys. Acta, 541, 96-106 (1978).

21) L. Cariello, A. de Santis, F. Fiore, R. Piccoli, A. Spagnuolo, L. Zanetti, and A. Parante: Calitoxin, a neurotoxic peptide from the sea anemone Calliactis parasitica: amino acid sequence and electrophysiological properties. Biochemistry, 28, 2484-2489 (1989).

22) U. E. Friese: Sea Anemones as a Hobby, T. F. H. Publications, Neptune City, 1993, pp. 144-149.

23) K. Shiomi, E. Tanaka, H. Yamanaka, and T. Kikuchi: Isolation and characterization of a lethal hemolysin in the sea anemone Parasicyonis actinostoloides. Toxicon, 23, 865-874 (1985).

24) O. H. Lowry, N. J. Rosebrough, A. L. Farr, and R. J. Randall: Protein measurement with the folin phenol reagent. J. Biol. Chem., 193, 265-275 (1951).

25) R. Beress, L. Beress, and G. Wunderer: Purification and characterization of four polypeptides with neurotoxic activity from Condylactis aurantiaca. Hoppe-Seyler's Z. Physiol. Chem., 357, 409-414 (1976).

26) B. M. Olivera, W. R. Gray, R. Zeikus, J. M. McIntosh, J. Varga, J. River, V. de Santos, and L. J. Cruz: Peptide neurotoxins from fish-hunting cone snails. Science, 230, 1338-1343 (1985). 